\title{
Masalah dan Pengembangan Formulasi Obat untuk Bentuk Dosis Anak-Anak
}

\author{
Aslamnur Fikri Ramadhana ${ }^{1, *}$, Rini Hendriani ${ }^{2}$ \\ ${ }^{1}$ Program Studi Sarjana Farmasi, Fakultas Farmasi, Universitas Padjadjaran \\ ${ }^{2}$ Departemen Farmakologi dan Farmasi Klinik, Fakultas Farmasi, Universitas Padjadjaran \\ *email: aslamnur28@gmail.com \\ (Submit 9/8/2019, Diterima 12/8/2019)
}

\begin{abstract}
Abstrak
Obat sering digunakan masyarakat sehari-hari, termasuk oleh anak-anak. Ada berbagai alasan untuk formulasi obat menjadi bentuk sediaan yang sesuai, contohnya untuk pengukuran dosis yang akurat. Review artikel ini bertujuan mengetahui masalah dalam formulasi bentuk dosis untuk anak-anak dan penelitian yang mengembangkan bentuk sediaan sesuai dosis untuk anak-anak. Metode yang dilakukan adalah dengan review jurnal dari tahun 1994 sampai tahun 2019. Diperlukan bentuk sediaan yang sesuai dengan kondisi dan usia anak-anak. Rasa yang tidak enak menjadi masalah dalam formulasi dan hambatan dalam terapi. Tablet dispersible, bubuk butiran, pellet, atau taburan rekonstitusi sering digunakan pada bayi tetapi rasanya perlu ditutupi dan pemberian tanpa air tidak cocok untuk semua umur. Beberapa penelitian melakukan pengembangan formulasi yang dapat diterima untuk anak-anak seperti tablet disintegrasi cepat cetirizine gydrochloride, fast-dissolving tablet untuk pengobatan antiretroviral, tablet pelarut susu dan tablet hisap paracetamol, suspensi oral deksametason, hidroklorotiazid, spironolakton, dan fenitoin, tablet orodispersible, dan sirup ranitidine hidroklorida dari tablet ranitidine hidroklorida. Dengan demikian masalah bentuk dosis anak-anak dan penelitian pengembangan bentuk dosis anak-anak dapat diberi solusi.
\end{abstract}

Kata kunci: pengembangan formulasi obat, bentuk dosis, anak-anak

\section{Outline}

- Pendahuluan

- Metode

- Pembahasan

- Kesimpulan

- Daftar Pustaka

\section{Pendahuluan}

Obat sering digunakan dalam kehidupan masyarakat sehari-hari. Industri farmasi terus menghasilkan obat baru setiap tahunnya untuk memenuhi kebutuhan pasar akan obat yang efektif dan terjangkau. Metode formulasi dan jenis sediaan baru juga terus dikembangkan untuk meningkatkan efektifitas obat maupun kenyamanan pasien. 
Bentuk sediaan tablet yang ditelan utuh, hancur, dan melepaskan obat dengan cepat di saluran pencernaan masih tetap menjadi formulasi pilihan dari sudut pandang manufaktur serta dari sudut pandang penerimaan pasien. Dengan demikian, obat yang diberikan dalam bentuk tablet harus hancur sebelum diserap dan diangkut ke sistem sirkulasi (Balasubramaniam et. al, 2008).

Ada berbagai alasan untuk memilih bentuk sediaan yang sesuai; salah satu yang paling penting berhubungan dengan pengukuran dosis yang tepat. Banyak obat yang efektif dalam dosis kecil dan hanya perlu diberikan sebesar miligram atau mikrogram. Untuk anak-anak jumlah obat yang diperlukan untuk dosis beragam berdasarkan usia dan berat badan. Obat harus diencerkan dalam pembawa yang memungkinkan pengukuran dosis yang akurat dan nyaman. Obat juga harus dilindungi selama masa penyimpanan dari degradrasi, misalnya oleh oksigen dan kelembaban dan, bila diberikan secara oral, mungkin memerlukan perlindungan dari penguraian oleh asam lambung. Rasa dan bau harus ditutupi dalam pembuatan sediaan cair dari obat yang tidak dapat larut atau tidak stabil (Nunn dan Williams, 2005).

Kesulitan dalam menelan tablet bisa terjadi pada semua kelompok usia dan dapat memperburuk keadaan pasien dan mengurangi efektivitas obat. Kesulitan menelan sering kali terjadi pada pasien anak-anak, usia lanjut, dan pasien dengan gangguan kejiwaan. Tablet merupakan sediaan pilihan untuk berbagai pengobatan karena sederhana, bersifat serba guna, nyaman, dan dapat diterima pasien (Avulapati et. al, 2011). Mencampur obat dalam bahan makanan adalah salah satu cara untuk menutupi rasa obat-obatan dan membantu menelan obat. Namun, banyak aspek seperti nilai viskositas, $\mathrm{pH}$, lemak dan kadar gula yang harus dipertimbangkan dan dievaluasi. Untuk menghindari penggunaan panel sensorik manusia yang mahal, maka studi pada tema ini meggunakan model hewan dan sensor elektronik untuk menilai rasa formulasi pediatrik (Immohr LI et al, 2016 dan Tiwari RV et al, 2015).

Penelitian telah menunjukkan bahwa anak paling kecil sekalipun telah dapat menelan sediaan solid dalam ukuran kecil (Klingmann, 2016). Oleh karena itu perlu diketahui masalah pada bentuk dosis anak-anak dan pengembangan formulasi obat untuk bentuk dosis anak-anak.

\section{Metode}

Metode yang digunakan adalah review dari 15 jurnal Antara tahun 1994 sampai 2019. Data yang didapat diperoleh berdasarkan pencarian jurnal tentang pengembangan formulasi obat untuk dosis anak. Kata kunci yang digunakan adalah "tablet formulation development for pediatric journal", "formulation development for pediatric journal", dan "drug formulation development for pediatric journal".

\section{Pembahasan}

Masa kanak-kanak ditandai dengan periode pertumbuhan, pematangan, dan perkembangan yang cepat. Ukuran dosis yang diperlukan selama masa kanak-kanak dan remaja mengalami perubahan yang dapat mencapai lima puluh kali lipat. 
Ada juga perubahan signifikan dalam kemampuan untuk menangani berbagai bentuk sediaan dengan obat-obatan cair volume kecil yang sesuai untuk penggunaan oral pada kelompok usia yang lebih muda; obat-obatan cair dan formulasi yang cepat larut cocok untuk sebagian besar usia dan tablet dan kapsul cocok digunakan pada remaja (Nunn dan Williams, 2005).

Praktik anak membutuhkan berbagai bentuk sediaan yang dapat diterima pada usia dan kemampuan yang berbeda serta berbagai kekuatan atau konsentrasi yang memungkinkan pemberian dosis pada usia yang tepat. Anak-anak yang sakit parah membutuhkan pemberian obat intravena dan akan lebih menyukai suntikan intramuskular yang sering. Pemberian secara oral untuk penyakit yang tidak serius dan pemberian jangka panjang lebih disukai, tetapi rute lain seperti bukal, hidung, transdermal dan dubur dapat berguna dalam keadaan tertentu (Nunn dan Williams, 2005).

Rasa pahit yang terdapat pada obat dianggap telah berevolusi sebagai pencegahan terhadap menelan zat beracun (Glendinning, 1994). Hambatan utama dalam pengembangan formulasi cairan oral adalah obat yang menutupi rasa obat karena lebih dari $90 \%$ dokter anak di AS melaporkan bahwa rasa obat adalah hambatan terbesar untuk menyelesaikan pengobatan (Milne, 2008). Dalam beberapa kasus, penutupan rasa secara sederhana tidak cukup dan diperlukan formulasi yang lebih kompleks untuk menyembunyikan rasa obat.

Eksipien yang digunakan dalam pengembangan suatu produk harus aman dan dapat diterima untuk digunakan pada anak-anak. Eksipien biasanya digunakan untuk mengoptimalkan formulasi obat, untuk meningkatkan rasa obat, masa penyimpanan obat, dan atau proses pembuatan. Ada eksipien tertentu yang tidak boleh digunakan dalam obat-obatan untuk anak-anak karena eksipien tersebut dapat menghambat perkembangan organ yang sedang berlangsung, misalnya, etanol, propilen glikol, benzil alkohol dan paraben. Konsentrasi elektrolit ketika mengembangkan obat-obatan untuk neonatus harus dipertimbangkan karena fungsi ginjal mungkin belum sempurna (Tuleu, 2013).

Penggunaan tablet dispersible, bubuk, butiran, pelet atau taburan untuk rekonstitusi adalah strategi populer dalam pengembangan formulasi pediatrik karena produk padat biasanya memiliki stabilitas yang lebih baik daripada sediaan cair. Namun, produkproduk yang dilarutkan ini juga perlu ditutupi. Rekonstitusi dapat terjadi baik pada titik pengeluaran atau pada titik pemberian tergantung pada produk. Instruksi untuk rekonstitusi dapat sulit dipahami untuk individu yang tidak terlatih, namun produk akhir harus mengandung dosis yang tepat untuk pasien. Jika padatan untuk rekonstitusi ini diberikan tanpa air, sediaan tersebut hanya cocok untuk bayi yang mendapat makanan padat (biasanya $>6$ bulan). Rentang usia minimum untuk padatan dengan ukuran partikel yang lebih besar mungkin lebih tinggi karena risiko aspirasi atau tersedak (Batchelor dan Marriott, 2015). 
Pada formulasi tablet Cetirizine Hydrochloride untuk anak-anak digunakan jenis fast disintegration tablet. Berdasarkan hasil uji maka dipilihlah Sodium Starch Glycolate 4\% sebagai superdisintegran. Peran superdisintegrant Sodium Starch Glycolate menyebabkan hidrofilisitas dan pembengkakan yang menyebabkan disintegrasi cepat. Sodium Starch Glycolate menyerap air dengan cepat dan membesar dalam air hingga $200-300 \%$ dan hancur dengan cepat. Sodium Starch Glycolate digunakan sebagai superdisintegran dalam formulasi tablet pada konsentrasi 4-6\%. Waktu disintegrasi sebenarnya dapat meningkat pada konsesntrasi atas $8 \%$ karena pembentukan gel dan efek penghasil viskositas berikutnya. Microcrystalline Cellulose konsentrasi $1 \%$ dipilih sebagai pengikat untuk formulasi tablet Cetirizine Hydrochloride FDT. Bahan yang larut dalam air seperti PVP K-30 cenderung larut daripada hancur, sedangkan bahan yang tidak larut seperti MCC umumnya menghasilkan tablet yang terdisintegrasi cepat. Karena adanya pori, cairan diambil ke jalur ini melalui kerja kapiler dan pecahnya ikatan antarpartikulat menyebabkan tablet pecah. Setelah tablet dicetak kemudian tablet dievaluasi dan didapat bahwa formula tablet Cetirizine Hydrochloride FDT memenuhi persyaratan (Sharma et. al, 2015).

Pada pembuatan fast-dissolving tablet untuk pengobatan antiretroviral digunakan metode freeze drying. Tujuan dari penambahan pengemulsi nonionik Tween 20 adalah untuk meminimalkan residu dan membantu melarutkan komponen obat. Mannitol digunakan tidak hanya sebagai agen bulking kristal untuk memberikan sifat penanganan yang baik, tetapi juga untuk menambah rasa manis. CMC adalah agen pengisi untuk menambah berat tablet dan meningkatkan sifat penanganan FDT secara keseluruhan. Lopinavir dan ritonavir bersifat sangat hidrofobik, dengan kelarutan dalam air sekitar $1 \mu \mathrm{g} / \mathrm{mL}$ dan koefisien partisi oktanol-air $(\log \mathrm{P})>4$. Hampir $50 \%$ dari berat tablet $(210 \mathrm{mg})$ berasal dari 2 komponen obat, yang dilarutkan pada konsentrasi 80 dan $20 \mathrm{mg} / \mathrm{mL}$ untuk lopinavir dan ritonavir, masing-masing, dengan adanya penstabil susu dan polimer. Salah satu penjelasan untuk peningkatan kelarutan (peningkatan 10.000 kali lipat) dalam formulasi air adalah adanya surfaktan yang dikombinasikan dengan kasein fosfoprotein dalam susu. Kasein dapat meningkatkan kelarutan obat melalui misel, dibantu oleh Tween 20. Tablet juga tidak mengalami perubahan setelah uji stabilitas dipercepat pada suhu $40^{\circ} \mathrm{C}$ dan kelembaban $75 \%$. Tablet yang dihasilkan juga dapat dilarutkan dalam susu atau makanan cair lainnya (Lal et. al, 2017).

Paracetamol adalah obat yang sering digunakan pada anak-anak. Salah satu pengembangan tablet paracetamol adalah tablet pelarut susu. Berbagai cara menutupi rasa dievaluasi, di mana dalam pengecapan rasa dilakukan dengan menggunakan $\beta$ siklodekstrin. Eksipien seperti manitol, sukrosa, sukralosa, natrium glikolat dan zat penyedap dievaluasi. Tablet dibuat dengan metode granulasi basah dan dievaluasi ketebalan, variasi berat, kadar obat, kekerasan, kerapuhan, waktu dispersi dan disolusi. Batch yang dioptimasi menunjukkan pelepasan obat lebih dari $85 \%$ dalam 15 menit pada tiga $\mathrm{pH}$ yang berbeda, bersama dengan semua sifat organoleptik yang diinginkan (Butani et. al, 2014). 
Paracetamol juga dapat diformulasikan dalam bentuk tablet hisap agar dapat dilepas secara perlahan untuk mengobati demam dan rasa sakit. Manfaat tablet hisap ini adalah meningkatkan bioavailabilitas, mengurangi iritasi lambung dengan melewati tahapan pertama metabolisme dan peningkatan onset aksi. Formulasi yang dibuat memiliki kekerasan $9-10 \mathrm{Kg} / \mathrm{cm}^{2}$, tidak berpasir, rasa di mulut terasa segar. Studi stabilitas formulasi yang dipilih juga dilakukan pada suhu $30^{\circ} \mathrm{C} \& 40^{\circ} \mathrm{C}$ selama enam bulan. Beberapa formulasi yang dipilih diuji untuk interaksi eksipien obat yang mengalami analisis Spektral IR. Studi disolusi obat in-vitro menunjukkan paling sedikit 70.012\% untuk PL3 dan maksimum 90.648\% untuk pelepasan obat PL4 dalam 30 menit. Tablet hisap yang dibentuk dapat memberikan formulasi alternatif yang menarik dalam mengurangi rasa sakit dan demam (Das dan Pattanayak, 2012).

Deksametason, hidroklorotiazid, spironolakton, dan fenitoin umumnya digunakan pada bayi, tetapi tidak ada formulasi yang tersedia secara komersial untuk kelompok usia ini. Dengan demikian, formulasi farmasi dari bentuk sediaan oral cair diperlukan untuk memungkinkan pemberian pada bayi yang baru lahir. Karena kelarutan dalam air bahan yang diinginkan buruk, suspensi oral ditambhakan dengan menggunakan Syrspend®SF-PH4 Dry, pembawa suspensi yang bebas bahan-bahan berbahaya. Kondisi penyimpanan digunakan $(5 \pm 3 \circ \mathrm{C}$ atau $22 \pm 4 \circ \mathrm{C})$, tidak ada degradasi bahan aktif yang signifikan pada suspensi oral campuran. Secara keseluruhan, hasil membuktikan bahwa stabilitas fisik dan kimia dari empat bentuk cairan oral selama 60 hari di bawah suhu penyimpanan biasa (Binson et. al, 2019).

Salah satu bentuk dosis yang dapat digunakan adalah tablet orodispersible. Tablet Orodispersible adalah teknologi inovatif di mana bentuk sediaan yang mengandung bahan-bahan farmasi aktif hancur dengan cepat dalam air liur dalam hitungan detik tanpa perlu air, memberikan kenyamanan optimal bagi pasien, sehingga sangat cocok untuk anak-anak, orang tua dan pasien dengan gangguan mental (Ghosh et. al, 2013). Sifat dispersible ini akibat penambahan superdisintegran ke formulasi sediaan yang melepaskan obat dalam mulut dan meningkatkan bioavailabilitas (Masareddy et. al, 2008). Tiga metode berbeda untuk penambahan disintegrasi digunakan, yaitu intra granular (dalam granula), ekstra granular (penambahan setelah granulasi) dan kombinasi kedua proses (Sekar et. al, 2008). Produk-produk ini menawarkan tingkat stabilitas farmasi dengan bentuk sediaan padat dan dapat diterima bahkan oleh pasien yang sangat muda. Namun, obat tersebut dibatasi oleh kekakuan dosis sama seperti tablet konvensional. Tablet orodisperible paling cocok untuk obat yang sangat larut, meskipun kelarutan obat perlu diseimbangkan dengan penutup rasa karena obat yang sangat larut akan memicu reseptor rasa pada lidah jika obat larut dalam air liur dalam rongga mulut (Mennela et. al, 2013).

Ranitidine hidroklorida adalah antagonis reseptor-H2 yang diindikasikan untuk ulkus duodenum. Obat ini digunakan untuk pengobatan ulkus lambung / duodenum dan GERD untuk neonatus dan anak-anak, dengan dosis masing-masing sebesar 1,5-2 mg / kg / 24 jam, q12j dan 1-5 mg / kgB / 24jam, q6-8j Untuk digunakan pada anak-anak diperlukan pemotongan tablet menjadi bagian-bagian yang lebih kecil untuk mendapatkan unit yang sesuai, karena ketiadaan bentuk farmasi yang lebih tepat seperti formulasi cair. 
Memotong tablet Ranitidine menjadi dua bagian dan empat bagian menyebabkan penyimpangan besar. Penyimpangan ini terkait dengan ada atau tidaknya garis skor. Ditunjukkan bahwa formulasi yang dibuat mempertahankan minimum $98 \%$ konsentrasi Ranitidine awal setelah 7 hari penyimpanan pada $25^{\circ} \mathrm{C}$ dan $4^{\circ} \mathrm{C}$ (Dosti dan Malaj, 2016).

\section{Kesimpulan}

Dari review artikel yang dilakukan dapat diketahui masalah yang terdapat pada bentuk dosis obat anak-anak seperti perlunya sediaan yang sesuai, rasa yang tidak enak, perlunya eksipien yang aman, dan obat yang tidak cocok untuk semua usia. Sedangkan diketahui contoh pengembangan bentuk dosis anak-anak seperti tablet disintegrasi cepat cetirizine gydrochloride, fast-dissolving tablet untuk pengobatan antiretroviral, tablet pelarut susu dan tablet hisap paracetamol, suspensi oral deksametason, hidroklorotiazid, spironolakton, dan fenitoin, tablet orodispersible, dan sirup ranitidine hidroklorida dari tablet ranitidine hidroklorida.

\section{Daftar Pustaka}

Avulapati, S., Roy, A. K., Shashidhar, K. R., dan Ugendarreddy, T. 2011. Formulation and evaluation of taste masked and fast disintegrating Losartan Potassium tablets. International Journal of Drug Development and Research, vol. 3(1): 45-51.

Balasubramaniam, J., Bindu, K., Rao,V. U., Ray D., Haldar R., dan A. Brzeczko, W. 2008. Effect of superdisintegrants on dissolution of cationic drugs. Dissolution Technologies, vol. 15(2): 18-25.

Batchelor, H. K. dan Marriott, J. F. 2015. Formulations for children: problems and solutions. Br J Clin Pharmacol. Vol. 79(3): 405-418.

Binson, G,, Beuzit, K, Migeot, V., Marco, L., Troussier, B., Venisse, N., dan Dupuis, A. 2019. Preparation and Physicochemical Stability of Liquid Oral Dosage Forms Free of Potentially Harmful Excipient Designed for Pediatric Patients. Pharmaceutics.11(4):190.

Das, Saumya dan Pattanayak, Dharmajit. 2012. FORMULATION DEVELOPMENT AND OPTIMIZATION OF MEDICATED LOZENGES FOR PEDIATRIC USE. International Journal of Pharmaceutical Sciences and Research, Vol. 3(1): 138-140.

Deepak, S., Singh, G., Kumar, D., dan Singh, M. 2015. Formulation Development and Evaluation of Fast Disintegrating Tablets of Salbutamol Sulphate, Cetirizine Hydrochloride in Combined Pharmaceutical Dosage Form: A New Era in Novel Drug Delivery for Pediatrics and Geriatrics. Journal of Drug Delivery, vol. 2015, pp. 1-10.

Dosti, Briseida dan Malaj, Ledjan. 2016. PEDIATRIC FORMULATION OF RANITIDINE USING FROM COMMERCIALLY AVAILABLE TABLETS IN ALBANIA. International Journal of Pharma Sciences and Research (IJPSR). Vol. 7(03): 168-171. 
Ghosh, T., Ghosh, A., dan Prasad, D. 2013. A review on orodispersible tablets - A novel formulation for oral drug delivery system and its future prospective. Indo American journal of pharmaceutical research. Vol. 3(1).

Glendinning Jl. 1994. Is the bitter rejection response always adaptive? Physiol Behav. Vol. 56(6):1217-1227.

Immohr, L. I., Hedfeld, C., Lang, A., dan Pein-Hackelbusch, M. 2016. Suitability of Etongue sensors to sssess tastemasking of pediatric liquids by different beverages considering their physico-chemical properties. AAPS PharmSciTech. Vol. 18(2): 330340 .

Klingmann, V. 2016. Acceptability of mini-tablets in young children: results from three prospective cross-over studies. AAPS PharmSciTech. Vol.18(2): 263-266.

Lal, M., Lai, M., Estrada, M., dan Zhu, C. 2017. Developing a Flexible Pediatric Dosage Form for Antiretroviral Therapy: A Fast-Dissolving Tablet. Journal of Pharmaceutical Sciences, 106, pp. 2173-2177.

Masareddy, R. S., Kadia, R. V., dan Manvi, F. V. 2008. Development of mouth dissolving tablets of clozapine using two different techniques. Indian J Pharm Sci. Vol. 70(4):526528.

Mennella, J. A., Spector, A. C., Reed, D.R., dan Coldwell, S. E. 2013. The bad taste of medicines: overview of basic research on bitter taste. Clin Ther. Vol. 35(8):1225-1246. Milne, C.P. dan Bruss, J.B. 2008. The economics of pediatric formulation development for off-patent drugs. Clin Ther. Vol. 30(11):2133-2145.

Nunn, Tony dan Williams, Julie. 2005. Formulation of medicines for children. British Journal of Clinical Pharmacology. Vol. 59(6): 674-676.

Shah, H., Butani, S., dan Parikh, D. 2014. Formulation development and optimization of milk dissolving tablets as a novel pediatric dosage form. International journal of drug formulation and research. Vol. 5(2):84-96.

Tiwari, R. V., Polk, A. N., Patil, H., Ye, X., Pimparade, M. B., dan Repka, M. A. 2015. Rat palatability study for taste assessment of caffeine citrate formulation prepared via hot-melt extrusion technology. AAPS PharmSciTech. Vol. 18(2).

Tuleu, C. dan Breitkreutz, J. 2013. Educational Paper: formulation-related issues in pediatric clinical pharmacology. Eur J Pediatr. Vol. 172(6):717-720.

Vasanthakumar, S. dan Chellan, R. V. 2008. Immediate release tablets of telmisartan using superdisintegrant-formulation, evaluation and stability studies. Chem Pharm Bull (Tokyo). Vol. 56(4):575-7. 